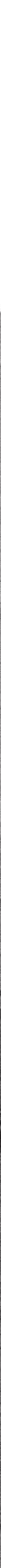
$x^{x}$ (a) 


\title{
ALBERT O. HIRSCHMAN: IDEALISTA PRAGMÁTICO
}

\author{
JEREMY ADELMAN \\ TRADUÇÃO DE OTACílio NUNES
}

[1] Hirschman, Albert O. Journeys towards progress: studies of economic policy-making in Latin America. Nova York: Twentieth Century Fund, 1963.
No curso de uma longa carreira, Albert $\mathrm{O}$. Hirschman tornou-se muitas coisas para muitas pessoas. Dissidente, reformista, transgressor, iconoclasta e ícone, historiador, psicólogo, pesquisador de campo e teórico, ele foi uma das raras figuras do século XX a situar-se acima de nossas áreas e disciplinas profissionais, e, no entanto, as moldou de maneiras que ainda estamos tentando entender. Em alguns casos, como na virada comportamental do cientista social, ele foi um economista adiante de seu tempo. Por essa razão, Hirschman tem sido difícil de categorizar.

Este ensaio se concentra em um aspecto do que ele chamava "um estilo cognitivo". Hirschman tinha a capacidade de cavar os lugares- comuns da vida - atos, palavras, discursos, comportamentos - para extrair novos modos de entender a vida social e a experiência do mercado. Seu estilo privilegiava um tipo diferente de dados - não tabelas de números ou "estudos de caso" estilizados - e uma estratégia de tratamento diferente. A orientação refletia uma preferência pessoal por um modo de olhar para o mundo e derivar conceitos interpretativos. $\mathrm{Na}$ verdade, Hirschman começava por olhar, observar e erguer uma "lanterna empírica" para a ciência social, como ele disse em Journeys towards progress [Jornadas rumo ao progresso] ${ }^{1}$, um estudo clássico dos efeitos da reforma na América Latina no começo da década de 1960 e um esforço para contrabalançar a atenção da direita e da esquerda ao fantasma da revolução. Mesmo nesse volume original, os "estudos de caso" da reforma no Brasil, no Chile e na Colômbia eram de fato mais histórias intelectuais da imaginação reformista do que análise cuidadosamente dosada. A observação precedia os conceitos. É claro que isso não significava que sua mente era uma tabula rasa, a ser gravada com anotações e visões. Hirschman portava uma chave mestra; ela seexibia em seu estilo, e não na tematização de metodologias explicativas abstratas.

Uma parte da chave envolvia escala. Hirschman começava pequeno para construir grande. Ele gostava das pequenas coisas negligenciadas, imperceptíveis, enterradas na gramática do cotidiano, e encontrava nelas rotas surpreendentes para pensar futuros alternativos. 
A lente para focalizar o aparentemente desimportante veio do cunhado de Hirschman, Eugenio Colorni, mas Hirschman se apropriou totalmente do estilo; ela também o tornou verdadeiramente singular. A preferência por escalas menores não refletia falta de ambição. Longe disso. Hirschman tinha um projeto que transcendia as normas da ciência social profissionalizada e desafiava a categorização fácil. Sua busca era para revelar como atos de imaginação intelectual podiam liberar amplas possibilidades. Ao encontrar fissuras mesmo nas estruturas mais impenetráveis, podiam-se criar aberturas e alternativas prospectivas. Essas eram tarefas para o intelectual. E isso era a fonte tanto do idealismo pragmático de Hirschman quanto de uma tensão com as disciplinas dominantes.

Muitas vezes, essa disposição significava contestar certezas estabelecidas, desde o tipo catastrofista ou fútil até a convicção eufórica de que se pode mudar tudo de uma só vez - dadas as "condições necessárias". Essas palavras eram ingredientes básicos da dieta da ciência social; poucas foram mais responsáveis por levar acadêmicos a correr atrás do próprio rabo. Entre aqueles com quem Hirschman boxeava incluíam-se desde pregadores de ortodoxias comunistas na década de 1930 ou planejadores econômicos liberais do "Big Push" [Grande Impulso] na década de 1960, até os apóstolos reacionários da década de 1980. No meio-tempo houve uma discussão solidária contínua com estruturalistas, na década de 1960, na América Latina, e neoliberais, na década de 1980. Em vez de brandir modelos grandiosos de sociedade ou história, Hirschman preferia a modéstia - o que o fazia voltar a abordagens discretas, não convencionais. Entre seus alvos estavam os gurus estabelecidos do "crescimento equilibrado" para o Terceiro Mundo, a crença de que os economistas podiam induzir o desenvolvimento movendo simultaneamente as partes complexas de uma economia inteira em perfeita conformidade. Hirschman adotava a visão contrastante. Optava por uma abordagem mais parcial, desequilibrada, que favorecia o foco estratégico em detrimento do alcance abrangente. Assim ele resumiu sua visão: "Olhar para o crescimento desequilibrado significa [...] olhar para a dinâmica do processo de desenvolvimento no pequeno. Mas talvez esteja mais do que na hora de fazermos exatamente isso" ${ }^{2}$.

Aescala não tinha a ver apenas com preferências observacionais ou método científico. Ela aparece também no estilo narrativo de Hirschman. Ele era um pensador mais que original; era também um mestre do ensaio. Seus ensaios são uma forma de arte: um uso econômico das palavras para dizer tanto. Ajudava que ele fosse um buscador minucioso da mot juste e do aforismo perfeito. Não é só a magnitude de sua análise que os leitores veem em funcionamento; é também o comprometimento de Hirschman com a ideia de que o modo como nos
[2] Hirschman, A. O. "The economics of development planning". Institute on ICA Development Programming, 5/15/1959, Strategy Papers, Arquivos Albert O. Hirschman (АОНР), Biblioteca Seeley Mudd, Universidade Princeton. Este seria publicado mais tarde como prefácio à edição em brochura de 1961. 
comportamos (o domínio do psicólogo) está ligado à experiência do mercado (o território do economista), que afeta a vida civil e política (o habitus do cientista político ou sociólogo).

Além disso, os conceitos que usamos têm, por sua vez, história. A prosa de Hirschman é cheia de lembretes de que alguns insights básicos vieram de uma época em que as ciências humanas estavam livres das disciplinas da academia moderna - e por isso ele tinha tanto afeto por ler, reler e citar os clássicos. Ler Hirschman é sentir-se diante de toda uma tradição de pensamento humanista. Com o desenrolar do século xx, um número cada vez menor de intelectuais era capaz de invocar sua amplitude; nossas ciências sociais se tornaram crescentemente trinchadas em províncias muradas chamadas "disciplinas". Cruzá-las agora parece muitas vezes forçado ou canhestro - um dos motivos pelos quais a capacidade de Hirschman de cruzar fronteiras de conhecimento parece tão sem esforço, quase natural. Outro motivo é que ele era simplesmente um autor talentoso, e concebia as ciências sociais como um ramo da literatura. Para os nostálgicos entre nós, a prosa de Hirschman é um lembrete de uma época anterior, que, sejamos razoáveis, já passou. É raro encontrar um autor em nossos tempos tão à vontade com as ferramentas modernas do cientista social e ao mesmo tempo tão preocupado com a complexidade da condição humana que fosse capaz de trazer à vida os atritos e tensões que decorrem de olhar para nosso mundo nas junções da vida política, econômica e emocional.

O estilo era uma chave para entender o alcance de Hirschman, pois permitia que ele transgredisse fronteiras disciplinares e temas com o objetivo de rearranjá-los. O escopo em si já é assombroso. Os temas tratados por ele incluem como pensar sobre a industrialização na América Latina, a concepção de reforma para além do reparo, a relação entre imaginação e liderança, algumas das observações mais perspicazes sobre o pensamento convencional a respeito do mercado e reflexões sobre como nossos debates afetam a vida democrática. Economia, sociologia, teoria política, história intelectual - esses subcampos das ciências sociais são entretecidos como um compêndio. E o tempo todo encontramos humor, metáforas inesquecíveis, análise brilhante e a elegância de estilo que davam a Hirschman uma voz tão singular, ao mesmo tempo brincalhona e curiosa, mas provocativa e comprometida.

E, contudo, embora Hirschman tivesse um estilo, ele nunca se distanciou da história. Na verdade, ele via seus conceitos e ideias como profundamente embutidos na história que os fazia, não abstrações universais situadas fora do tempo ou acima da condição humana. Essa era talvez a razão mais importante pela qual o impulso nas ciências sociais para explicações universais, que dominava a academia, era um 
problema tão sério para ele. Embora fonte de muita frustração profissional, podia ser também um alvo para o humor de Hirschman. Como ele brincou com Clifford Geertz em 1976, muitos de seus colegas eram presas da "Primeira Lei das Ciências Sociais": "Sempre que um fenômeno no mundo social é plenamente explicado, ele cessa de operar"3.

A vida de Hirschman pode ser vista como uma parábola dos horrores e das esperanças do século XX. Por nele viver, buscou mudá-lo mesmo nos momentos mais sombrios; aprendeu a teorizar a partir da experiência, a construir conceitos a partir da observação. Essa aptidão foi o resultado de uma exposição inicial a Michel de Montaigne, o pai do ensaio. E seu encontro com Montaigne teve tudo a ver com o modo como um socialista comprometido lidava com a destruição do mundo cosmopolita em que foi criado.

Nascido em Berlim em 1915, Hirschman deixou a Alemanha no começo de 1933, com a ascensão de Hitler e a trágica morte de seu pai. Esse ano marcou o fim de um longo sonho para judeus como os Hirschmanns (o nome foi modificado quando Albert se mudou para os Estados Unidos), que escoravam sua fé no Iluminismo e na compensação que vinha com a assimilação em forma de direitos civis e políticos. Poderíamos dizer que o fim da adolescência fechou a porta de um sonho de menino, encarnado no espírito de tolerância, experimentação e reforma que associamos à República de Weimar. Mas não foi assim. Um amor por Goethe e uma dedicação a entender e lutar pelos valores cosmopolitas de sua república morta acompanharam Hirschman por toda a vida.

A fuga de Berlim foi a primeira de muitas; a intolerância o perseguiu de país em país. Alguém mais vulnerável à amargura poderia ter considerado essa marca registrada da vida na era moderna um sinal de declínio em relação aos ideais elevados do Iluminismo. O nome de Hannah Arendt vem à mente, como os de tantos outros exilados da Mitteleuropa jogados no mundo para transformar sua paisagem artística e intelectual, para espalhar, compreensivelmente, uma sombra de dúvida e pessimismo sobre a condição moderna.

Mas Hirschman não era um deles. Na verdade, uma característica emblemática de sua política - e de seu gênio intelectual - era a capacidade de ver que o que parece imutável, intratável e impenetrável à mudança podia ser uma fonte de opções. Com um pouco de imaginação, algum pensamento lateral e ousadia, as alternativas estavam quase sempreali. "Não estamos interessados no queé(escassamente) possível, em vez de no que é provável?", perguntou-se em privado em seu diário. Em vez de se obsedar com a certeza e a predição - que o faziam lembrar-se da prescrição de Flaubert contra la rage de vouloirconclure [a raiva de querer concluir] como algo que certamente nos leva a becos sem saída e resultados preestabelecidos - , não deveríamos tal-
[3] "Conversation with Clifford Geertz and Albert Hirschman on 'The hungry, crowded, competitive world"', АОНP. 
vez ser mais humildes e esperançosos? Seu credo fincava uma bandeira contra o desencanto paralisante com a reforma, o desenvolvimento e a modernização ao apresentar ao mundo uma figura que ele chamou de "o possibilista" em um ensaio famoso escrito não muito depois de uma viagem à Argentina, em 1970. A bússola ética para o possibilista era uma noção de liberdade definida, como dizia Hirschman, como "o direito de um futuro não projetado", a liberdade de explorar destinos que não eram previstos pela lei de ferro da ciência social.

Os elementos do pensamento de Hirschman foram colhidos em uma vida de viver e agir no mundo. Embora tivesse um intelecto precioso desde quando era garoto, foi da combinação de sua vita contemplativa e sua vita activa que ele montou uma visão de mundo. A fuga de Berlim o levou a Paris, onde se juntou ao número crescente de refugiados - mencheviques russos, socialistas italianos, comunistas alemães. Em Paris, e depois na London School of Economics e na Universidade de Trieste, aprendeu economia - embora, talvez, seja mais correto dizer que ele se ensinou economia. De qualquer maneira, desde o início ele compôs uma mistura singular a partir da leitura de clássicos como Adam Smith e Karl Marx, debates franceses sobre balanço de pagamentos e preocupações italianas com a produção industrial. Foi contra o pano de fundo da Depressão e da preocupação com as causas e as soluções para o desemprego em massa e a disseminação da autarquia econômica e do imperialismo que ele fez suas primeiras investidas na disciplina. Há uma sensação de que ele, desde o princípio, não era limitado por nenhuma espécie de ortodoxia econômica. Enquanto Hirschman estava em Londres, Keynes publicou sua monumental Teoria geral. Os detratores de Keynes, Lionel Robbins e Friedrich Hayek, eram figuras imponentes na London School of Economics. E, no entanto, Hirschman jamais se entusiasmou por afirmações teóricas grandiosas rivais. Seu objetivo era outro: compreender as raízes subjacentes da comoção econômica da Europa, preocupação que o levaria no fim às instabilidades e ao desequilíbrio do processo de desenvolvimento em termos mais gerais.

Além da provação do exílio ou da economia da Grande Depressão, também o moldou a crise política que se espalhou por toda a Europa. Paris substituíra Berlim como o ponto focal da vida de Hirschman; esse período foi marcado por idas e vindas de lá para Inglaterra, Espanha e Itália. Foi em Paris que começou uma segunda educação intelectual e política, que o apartou de suas raízes idealistas alemãs. A capital francesa era um centro de irradiação de uma diáspora continental: russos, italianos, alemães, espanhóis, austríacos e tchecos. Hirschman logo se viu afastando-se da esquerda alemã à qual se filiara e derivando para um círculo italiano muito menos preocupado com obtero diagnóstico ideológico "correto" do que com mudar a história por meio da ação. 
Especialmente sob o fascínio de Eugenio Colorni, cuja heterodoxia filosófica e política era um modelo, Hirschman se tornou muito mais eclético em suas leituras. Havia uma ligação familiar: Colorni tinha cortejado a irmã de Hirschman, Ursula, e se casado com ela, e se tornou a influência intelectual mais importante no estilo cognitivo de Hirschman. A relação, fermentada por leituras em comum e por longas conversas, aprofundou-se quando Hirschman se mudou para Trieste, para onde Colorni e Ursula tinham se mudado um ano antes, depois de uma breve e amarga experiência lutando do lado republicano durante a Guerra Civil Espanhola.

Colorni vinha de uma variante italiana do mesmo cosmopolitismo europeu. Judeu assimilado, era membro de um movimento que tentava combinar, assim como Hirschman, o espírito amante da liberdade do liberalismo com o impulso em busca de justiça do socialismo. Essa tradição democrática eclética é talvez mais bem representada pelo falecido Norberto Bobbio, com quem se poderia emparelhar Hirschman como arquétipo de um estilo acadêmico diferente, mais aberto; nenhum deles perdia de vista os aspectos políticos da atividade intelectual; ambos eram ensaístas. Foi Colorni quem inculcou Montaigne em Hirschman e a beleza do gênero do ensaio. Foi Colorni quem observou que a liberdade do ensaio era um análogo de um modo mais aberto de pensar sobre política. Eles passavam muitas horas juntos, em Paris e Trieste, e especialmente no retiro da família Colorni em Forte di Marmi, no litoral da Toscana, cruzando juntos as fronteiras das ciências humanas.

Desde Trieste, Hirschman e Montaigne não mais se separariam; o mesmo não se deu com Hirschman e Colorni, que foi morto a tiros por assassinos fascistas nas ruas de Roma.

Uma característica importante de Montaigne informou o espírito de Hirschman: os insights são extraídos igualmente da fonte da experiência vivida. O francês prescrevia a seus leitores "observar, observare observar". Mas, diferentemente de Montaigne, Hirschman tinha uma experiência vivida feita de cruzamentos de fronteiras, de saídas que estavam estreitamente ligadas a suas lealdades políticas; ele se tornou o que poderíamos chamar hoje um cosmopolita - embora Hirschman provavelmente se retraísse diante desse rótulo. Viver na Europa, em especial como ativista socialista, implicava de um modo básico comprometer-se com a luta contra o fascismo. Tão logo o Generalíssimo Franco se rebelou contra o governo republicano em Madri, os italianos em Paris começaram a organizar os primeiros voluntários e Hirschman estava entre eles. Semanas depois da irrupção da Guerra Civil Espanhola, em julho de 1936, ele estava em Barcelona. Lá ficou, combateu e foi ferido no front aragonês; quando o Partido Comunista buscou afirmar seu controle sobre milicianos, anarquistas e progres- 
[4] Hirschman, A. O. Exit, voice and loyalty: responses to decline in firms, organizations and states. Cambridge: Harvard University Press, 1970. sistas variados, Hirschman, horrorizado com a mesma intransigência que vira nos últimos dias da República de Weimar, partiu para a Itália para participar de um novo front da luta continental. Os decretos antissemitas de Mussolini em 1938 interromperam a temporada na Itália, embora não antes de Hirschman obter seu doutorado na Universidade de Trieste. Mais uma vez, uma fuga para Paris.

A guerra fez muitas pessoas ricochetearem mundo afora. $\mathrm{O}$ que havia de singular na mobilidade de Hirschman era que ela estava vinculada ao fato de ele ser um voluntário profissional nos exércitos de outros povos, não como mercenário, mas como partidário de uma causa. Para um dos grandes teóricos das reações humanas ao declínio organizacional, inscritas em sua obra pioneira Exit, voice and loyalty [Saída, voz e lealdade]4 (dedicada a Colorni), os envolvimentos e as decepções frequentes tinham uma longa história pessoal. Quando se tratava de tirania, não havia dúvida sobre onde estavam suas lealdades. Após 1939 ele ingressou em mais dois exércitos — o francês e depois o americano - para combater o fascismo. Em ambos os casos, ele o fez como estrangeiro. E, contudo, a vida de um soldado significava submeter-se às regras entorpecentes e à burocracia de uma organização de massa. Mais a seu gosto foi a colaboração com o jornalista americano Varian Fry em uma operação em Marselha que resgatou centenas de refugiados da Europa, entre eles Marc Chagall, Max Ernst, André Breton e Hannah Arendt. Aí estava uma forma furtiva de luta que atraía muito mais o temperamento de Hirschman — isto é, até que a polícia de Vichy o forçou a fugir pelos Pirineus.

É fácil esquecer que houve um tempo em que a vida da mente não era tão apartada do envolvimento no mundo. Durante grande parte da vida de Hirschman, a formação de um intelectual nem sempre implicava a formação de um acadêmico. Na verdade, no momento em que obteve seu primeiro cargo de economista, não foi trabalhar em uma universidade, mas no Federal Reserve Board, em Washington, no Plano Marshall e na reconstrução europeia. Além disso, ele já não era solteiro. Depois de fugir da Europa, foi para Berkeley, Califórnia. Lá conheceu sua mulher, Sarah Chapiro, filha de emigrados russos que a criaram em Paris e, sentindo o raiar da guerra, migraram para os Estados Unidos. Albert e Sarah teriam duas filhas e fariam da capital dos Estados Unidos sua casa, quando a paranoia reacionária da purgação macartista da sociedade civil americana o levou mais uma vez a cruzar fronteiras em busca de ambientes mais seguros - e, se possível, aventura. Em 1952 ele se mudou para a Colômbia com a mulhere as duas filhas.

Assim começou a latino-americanização de Hirschman, e com ela sua reinvenção. Alguns traços básicos de seu estilo estavam então se tornando claros. Ele não era um pensador ortodoxo. Desafiava a cate- 
gorização. E, em tempos sombrios, era ainda mais importante pensar diferentemente sobre a fonte do problema e os remédios potenciais. Mas foi o confronto com os desafios do desenvolvimento capitalista e da democracia na América Latina que trouxeram à tona sua imaginação. Na Colômbia ele trabalhou não em uma torre de marfim, mas como consultor, ajudando a lidar com problemas cotidianos de investimento em esquemas de irrigação e projetos habitacionais. De seus anos trabalhando e observando no campo vieram publicações que refariam sua carreira - e o catapultariam, na meia-idade, para as cidadelas da educação superior americana, Yale, Columbia, Harvard, e finalmente para o Instituto de Estudos Avançados, em Princeton.

Encontros na América Latina alimentaram um quarto de século de obra inovadora, de The strategy of economic developments ao seu negligenciado mas brilhante ensaio Getting ahead collectively: grassroots experiences in Latin America [Progredindo coletivamente: experiências de base na América Latina $]^{6}$. Mapear a obra de Hirschman é como traçar os encantos e desencantos do pensamento sobre desenvolvimento conforme elaborado por planejadores, funcionários do Banco Mundial, engenheiros e ativistas de base, praticantes da arte de fazer o progresso. Cabia ao economista, ele sentia, "cantar o épico" dos labores daqueles que trabalhavam nos campos do desenvolvimento. Previsivelmente, um de seus aforismos preferidos era a equiparação feita por Camus da mudança social a "um longo confronto entre o homem e uma situação". Essa sempre foi uma abordagem mais atraente do que a superconfiança descuidada na solvibilidade de todos os problemas ou do que o fatalismo de que nada pode ser propositadamente transformado.

Há um motivo que vale a pena notar no estilo narrativo de Hirschman: o delicado equilíbrio entre observação apaixonada e envolvimento crítico. Nele estava o conhecimento voltado para mudar os entendimentos do mundo. A experiência de leitura de um livro ou ensaio de Hirschman pretendia ser uma que desestabilizasse o senso comum e as ortodoxias. Estivesse ele lidando com os gurus do crescimento equilibrado na década de 1960 ou com os fanáticos "milton-friedmanitas" da década de 1980, o propósito de Hirschman era contestar certezas finais - observando que a busca do paradigma correto pode com frequência atrapalhar a compreensão dos aspectos mais básicos. Essa era uma aflição não apenas de autores na direita como também uma característica dos da esquerda. Costuma-se esquecer que em seu famoso livro expondo o jogo de palavras do que hoje chamamos apóstolos "neoliberais" em Rhetoric of reaction: perversity, futility, jeopardy [Retórica da reação: perversidade, futilidade, perigo] 7 , um capítulo foi dedicado a formas progressistas de intransigência.
[5] New Haven: Yale University Press, 1958.

[6] Boulder: Westview Press, 1984.
[7] Cambridge: Bellknap/Harvard University Press, 1991. 
[8] Princeton: Princeton University Press, 1977 .

Recebido para publicação em 13 de maio de 2013 .

\section{NOVOS ESTUDOS}

CEBRAP

96, julho 2013

pp. 5-13
O que tornou Hirschman tão original foi que ele emergiu das margens da universidade e, portanto, nunca foi verdadeiramente da universidade. Isso o liberava para cruzar fronteiras com grande desembaraço. O tédio de reuniões de corpo docente e os rituais da vida acadêmica o levavam às lágrimas.

E, no entanto, foi para intelectuais que Hirschman escreveu acima de tudo. Poderíamos dizer que os intelectuais eram tanto o assunto quanto o público-alvo de sua obra. Ao descobrir que um importante fator no desenvolvimento era o modo como os intelectuais imaginavam as possibilidades de progresso, Hirschman insistiu que o modo como entendemos o mundo afeta o modo como podemos mudá-lo; os intelectuais têm um papel decisivo no trabalho de criar campos de significado. Na década de 1960, ele instou os pensadores latino-americanos a superar seu pessimismo crônico; e fez o mesmo para o pensamento social americano na década de 1980 . No meio-tempo, ele escreveria um ensaio luminescente sobre a história do pensamento sobre capitalismo, The passions and the interests:political arguments for capitalism before its triumph [As paixões e os interesses: argumentos políticos para o capitalismo antes de seu triunfo $]^{8}$, precisamente para mostrar que a experiência do mercado era afetada pelas palavras e polêmicas inventadas e conduzidas por autores, com enormes consequências para as políticas públicas. A ele se seguiu uma série notável de ensaios sobre concepções rivais do mercado baseada em palestras que Hirschman fez em Paris no começo da década de 1980 - nas quais insistia que havia modos alternativos de pensar sobre economia e política, modos que eram mais humanos, mais criativos, e em última instância mais libertadores que o esquema produzido pelos empedernidos defensores e críticos do capitalismo.

Como Hirschman disse na última linha de The passions and the interests, talvez seja na história das ideias que possamos encontrar pistas para elevar o nível do debate. Poucos deixaram mais pistas precisamente para esse propósito do que ele. Seria difícil imaginar um momento melhor do que agora para elevar o debate.

JEREMY ADELMAN é professor de História da cátedra Walter Samuel Carpenter III de Civilização e Cultura Espanhola da Universidade Princeton (EUA). 